Article

\title{
Influence of Combined Action of Steel Fiber and MgO on Chloride Diffusion Resistance of Concrete
}

\author{
Feifei Jiang ${ }^{1,2, * \mathbb{D}}$, Min Deng ${ }^{1}$, Liwu Mo ${ }^{1}$ and Wenqing $\mathrm{Wu}^{3}$ \\ 1 State Key Laboratory of Materials-Oriented Chemical Engineering, College of Materials Science and \\ Engineering, Nanjing Tech University, Nanjing 211800, China; dengmin@njtech.edu.cn (M.D.); \\ andymoliwu@njtech.edu.cn (L.M.) \\ 2 College of Naval Architecture Civil Engineering, Jiangsu University of Science and Technology, \\ Zhangjiagang Campus, Suzhou 215600, China \\ 3 School of Transportation, Southeast University, Nanjing 210089, China; wuwenqing@seu.edu.cn \\ * Correspondence: 999620140019@just.edu.cn
}

Received: 24 March 2020; Accepted: 22 April 2020; Published: 24 April 2020

check for updates

\begin{abstract}
To improve the chloride diffusion resistance and durability of concrete, a new kind of steel fiber reinforced $\mathrm{MgO}$ concrete (SFRMC) was made by adding steel fiber and $\mathrm{MgO}$ to concrete simultaneously. With steel fiber for load bearing and expansion limiting, $\mathrm{MgO}$ as the expander, SFRMC has both the advantages of fiber reinforced concrete and expansion concrete. The influence of steel fiber and $\mathrm{MgO}$ on the strength and chloride diffusion resistance of concrete was evaluated by splitting tensile test and chloride diffusion test. Mercury intrusion porosimeter (MIP) and scanning electron microscopy (SEM) were used to study the microstructure of SFRMC. The results showed that the combined action of steel fiber and $\mathrm{MgO}$ reduced the porosity of concrete and the chloride diffusion coefficient (CDC), which could not be achieved by steel fiber and $\mathrm{MgO}$ separately. In the free state, the expansion energy produced by the hydration of $\mathrm{MgO}$ made the concrete expand outwards. However, under the constraint of steel fiber, the expansion energy was used to tension the fiber, resulting in self-stress. In this way, compared to reference concrete $\mathrm{RC}$, the tensile strength of SFRMC-1, SFRMC-2, and SFRMC-3 increased by $3.1 \%, 61.3 \%$, and $64.5 \%$, CDC decreased by $8.8 \%$, $36.7 \%$, and $33.1 \%$, and the porosity decreased by $6.2 \%, 18.4 \%$, and $20.6 \%$, respectively. In addition, the SEM observations demonstrated that the interfacial transition zone (ITZ) between fiber and matrix was denser in SFRMC, which contributed to reduce the diffusion of chloride ions in the concrete.
\end{abstract}

Keywords: steel fiber; $\mathrm{MgO}$ expansive agent; split tensile strength; chloride diffusion resistance; porosity; interfacial transition zone

\section{Introduction}

Steel fiber reinforced concrete (SFRC) is a kind of high-performance concrete which distributes steel fiber uniformly in the matrix. Due to the restraint of steel fibers, the development of cracks is restrained, which makes SFRC have higher crack resistance and good toughness [1]. Owing to these excellent properties, SFRC has been widely used in port structures and protection structures, especially in those structures with high requirements for diffusion resistance and crack resistance [2-4]. However, these structures mentioned above are often in direct contact with chlorine ions. When chloride ions diffuse into the concrete, they will cause corrosion of the steel bar, leading to cracking and affecting the safety of the structure $[5,6]$. Therefore, it is of great significance to reduce the chloride diffusion coefficient (CDC) of SFRC.

In recent years; many researchers have studied the chloride diffusion resistance of fiber reinforced concrete. Vahid compared the effects of different kinds of fibers on the resistance of concrete to chloride 
tolerance. He found that polypropylene fiber reduced CDC; while adding steel fibers significantly increased CDC [7]. Guo added $0.15 \%, 0.30 \%, 0.45 \%, 0.60 \%$ of basalt fiber into concrete and tested the pore structure and the chloride diffusion resistance. The results showed that by adding basalt fiber, the chloride diffusion resistance was improved, the minor harmful pores $(20-100 \mathrm{~nm})$ were increased, and the serious harmful pores $(>200 \mathrm{~nm})$ were significantly reduced [8]. Yan explored the effects of different amounts of basalt fiber (BF; 0.05, 0.1, 0.15, and $0.2 \mathrm{vol} \%$ ) on the chloride ion diffusion. He found that the inclusion of $0.05 \% \mathrm{BF}$ accelerated the diffusion of chloride ions from the coral aggregate; while a dosage of $\mathrm{BF}$ above $0.1 \%$ could suppress the diffusion of chloride ions [9]. Mahyuddin explored the effects of different amounts of coconut fiber $(0.6 \%, 1.2 \%, 1.8 \%$, and $2.4 \%)$ on mechanical property and chloride diffusion. He found that by adding coconut fiber, compressive and flexural strengths were increased to $13 \%$ and $9 \%$, respectively. However, in terms of durability, the chloride diffusion resistance was reduced [10]

Previous studies have confirmed that fiber can improve the mechanical properties of concrete [11-16], but there are different opinions on the chloride diffusion resistance. Some researchers think that fiber can enhance the chloride diffusion resistance of concrete, but the other researchers hold the opposite opinion. The main reason for different opinions is that fiber has both positive and negative effects in concrete. On the one hand, fiber reduces the shrinkage crack of concrete and improves the compactness of concrete. On the other hand, the fiber increases the number of ITZ between the fiber and the matrix, and the gap at the interface provides a channel for chloride diffusion. However, researchers have agreed that ITZ between fiber and matrix is the weakness of concrete, and the strength of ITZ has a great influence on the performance of concrete. To reduce the defect of ITZ, steel fiber and $\mathrm{MgO}$ were used simultaneously in this paper. The expansion of $\mathrm{MgO}$ was restrained by steel fiber, the void was filled, the porosity was reduced, and the strength of ITZ was improved.

From the view of reducing shrinkage cracks, the use of expansion agent is to use the expansion produced by hydration to compensate the shrinkage of concrete [17]. According to the differences in mineral composition of the expansive agent, the expansive agents currently sold in the market can be divided into five types: sulfide-aluminate expansive agent, lime expansive agent, iron powder expansive agent, $\mathrm{MgO}$ expansive agent, and compound expansive agent [18]. Among the above, $\mathrm{MgO}$ is one of the most excellent expansive agents. It has been widely used because of its stable hydration products, easy regulation of expansion performance, and no shrinkage in the later stage $[19,20]$.

By studying the advantages and disadvantages of fiber and $\mathrm{MgO}$, we found that steel fiber and $\mathrm{MgO}$ can be used together to give full play to the advantages of both materials. Different from SFRC, steel fiber not only plays a role in bridge connection, but also plays a role in limiting expansion in SFRMC. The three-dimensional distribution of steel fiber seriously restricts the expansion of $\mathrm{MgO}$, changes the expansion mode of $\mathrm{MgO}$, and makes the expansion from outward extension to inward extrusion, which greatly improves the compactness of SFRMC. Our previous research [21] has confirmed that SFRMC has excellent mechanical properties, but its durability has not been studied. In this paper, split tensile test, chloride diffusion test, mercury intrusion porosimeter MIP test, and scanning electron microscopy SEM test were conducted to study the combined effect of steel fiber and $\mathrm{MgO}$ on the tensile strength and chloride diffusion resistance of SFRMC. Through the analysis of pore structure, ITZ structure, the mechanism of SFRMC performance enhancement was studied. These data provided theoretical support for further application of SFRMC and opened up new application fields for MgO concrete and fiber reinforced concrete.

\section{Materials and Methods}

\subsection{Materials}

In this paper, the cement is Class 52.5 Ordinary Portland Cement (Shan Aluminum Cement Co., Ltd., Shandong, China). Fly ash was produced by Shenhua Huashou Power Co., Ltd in Shanghai, China. MgO was produced by Wuhan Sanyuan Special Building Materials co. LTD in Wuhan, China. 
The activity of $\mathrm{MgO}$ was $115 \mathrm{~s}$ and the specific surface area was $45.7 \mathrm{~m}^{2} / \mathrm{g}$. Figure 1 shows the mineral composition of $\mathrm{MgO}$. Table 1 summarizes the chemical composition of cement, Fly ash, and $\mathrm{MgO}$.

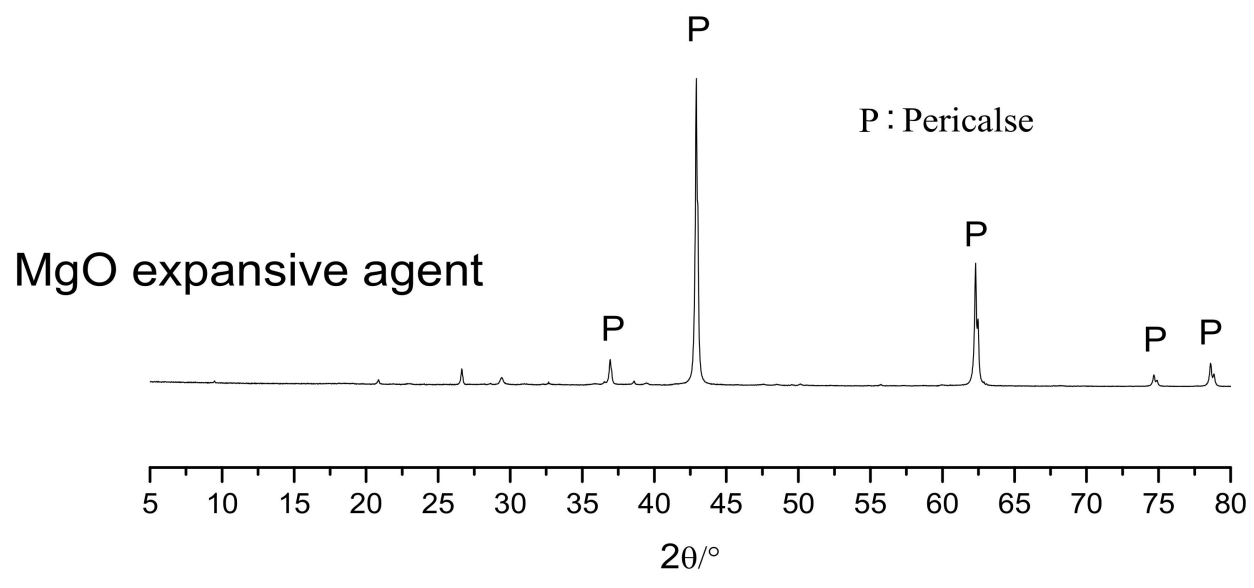

Figure 1. X-ray diffraction pattern of $\mathrm{MgO}$.

Table 1. Chemical composition of cement.

\begin{tabular}{ccccccccccc}
\hline \multirow{2}{*}{ Type } & \multicolumn{8}{c}{ Chemical Composition $/ \mathbf{w t} \%$} \\
\cline { 2 - 11 } & $\mathbf{C a O}$ & $\mathbf{M g O}$ & $\mathrm{Al}_{\mathbf{2}} \mathbf{O}_{\mathbf{3}}$ & $\mathrm{SiO}_{\mathbf{2}}$ & $\mathbf{F e}_{\mathbf{2}} \mathbf{O}_{\mathbf{3}}$ & $\mathbf{S O}_{\mathbf{3}}$ & $\mathbf{K}_{\mathbf{2}} \mathbf{O}$ & $\mathbf{N a}_{\mathbf{2}} \mathbf{O}$ & Loss & Total \\
\hline Cement & 60.51 & 2.18 & 6.34 & 22.02 & 3.05 & 1.86 & 0.47 & 0.23 & 1.96 & 98.62 \\
Fly ash & 5.01 & 1.03 & 34.18 & 48.91 & 5.22 & 1.20 & 0.89 & 0.62 & 1.50 & 98.56 \\
$\mathrm{MgO}$ & 3.19 & 85.44 & 0.73 & 4.45 & 0.42 & 0 & 0 & 0 & 4.49 & 98.72 \\
\hline
\end{tabular}

Continuously graded gravel with a size of 5-20 mm was used as the coarse aggregates. River sand with a fineness modulus of 2.94 was used as the fine aggregates. Steel fiber was produced by Zibo Shuanglian Building Materials co. LTD in China. The tensile strength of steel fiber was $520 \mathrm{MPa}$. The diameter of steel fiber was $0.58 \mathrm{~mm}$ and the length was $40 \mathrm{~mm}$. Figure 2 shows the specific morphology of steel fiber, which is a wave shape. Table 2 shows the mix proportion of the concrete used in this paper.

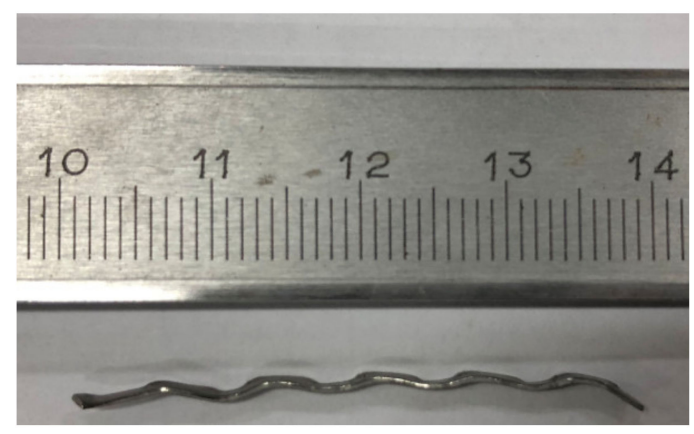

Figure 2. Photograph of steel fiber.

\subsection{Experimental}

The specific process and analysis method of this paper are shown in Figure 3. Cube blocks of $150^{*} 150^{*} 150 \mathrm{~mm}$ were poured to study the split tensile strength and cylinder specimens of $\varnothing 100 \times 50 \mathrm{~mm}$ were poured to study the chloride diffusion resistance. After casting, the molds filled with fresh concrete were placed on the high-frequency vibration table to vibrate until no obvious bubbles escaped. After $24 \mathrm{~h}$, the abrasives were removed and the concrete was transferred to the standard curing chamber $\left(20 \pm 2{ }^{\circ} \mathrm{C}, 95 \% R H\right)$. 
Table 2. Mix proportion of concrete.

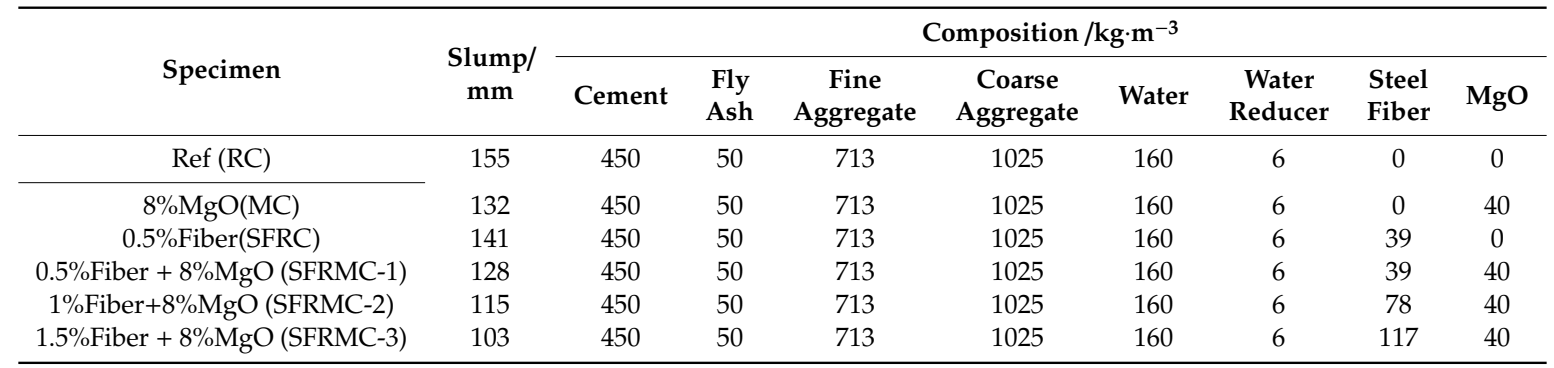

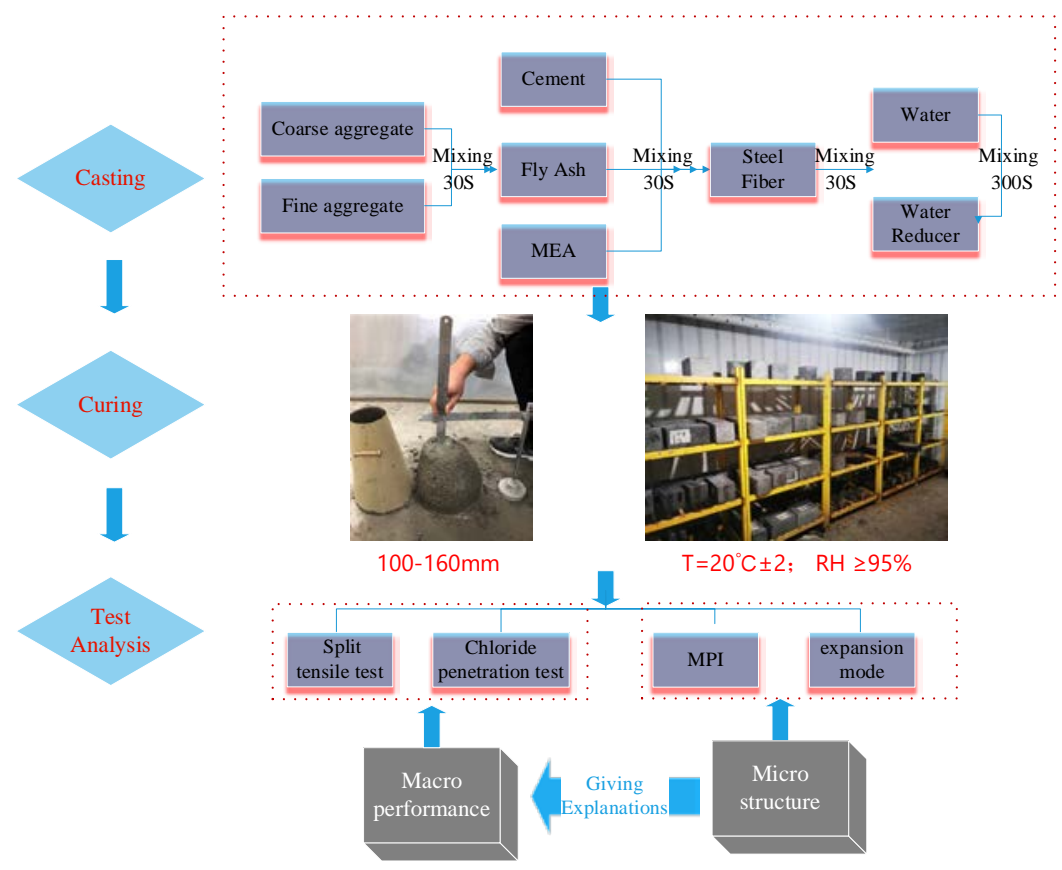

Figure 3. The specific process and analysis method.

\subsubsection{Split Tensile Test}

The split tensile strength test was conducted with reference to China Standard GB/T 50081-2016 [22]. The main equipment was the SYE-2000 pressure testing machine with a maximum load of $2000 \mathrm{kN}$. The size of the specimens was $150 \mathrm{~mm} \times 150 \mathrm{~mm} \times 150 \mathrm{~mm}$, and the mean value of the three specimens was taken as the tensile strength of the specimens (accurate to $0.01 \mathrm{Mpa}$ ). The loading rate was $0.06 \mathrm{Mpa} / \mathrm{s}$. The tensile strength was calculated according to Formula (1). The test diagram is shown in the Figure 4:

$$
f_{t s}=2 F / \pi A=0.637 F / A,
$$

where $f_{t s}$ is the tensile strength of concrete, in MPa; $F$ is the failure load of the test piece, in $\mathrm{N} ; A$ is the bearing area of the test piece, in $\mathrm{mm}^{2}$.

\subsubsection{Chloride Diffusion Test}

Normally, the main methods for measuring chloride diffusion resistance are slow method and fast method. Among them, the slow method is too time-consuming and seldom used in practice, while the fast method can measure the chloride diffusion resistance of materials in a short time. As the most typical of the rapid method, the electric flux method was first proposed by the Portland Cement Association of the United States in 1981 and has become the most widely used in the world. The principle of the method is to use the electric field to accelerate the ion transport. The ions penetrate through the specimen under the action of DC power. In this paper, the chloride diffusion resistance 
was evaluated by the flux transferred in accordance with the procedures described in ASTM C1202 [23]. The test device is shown in Figure 5.

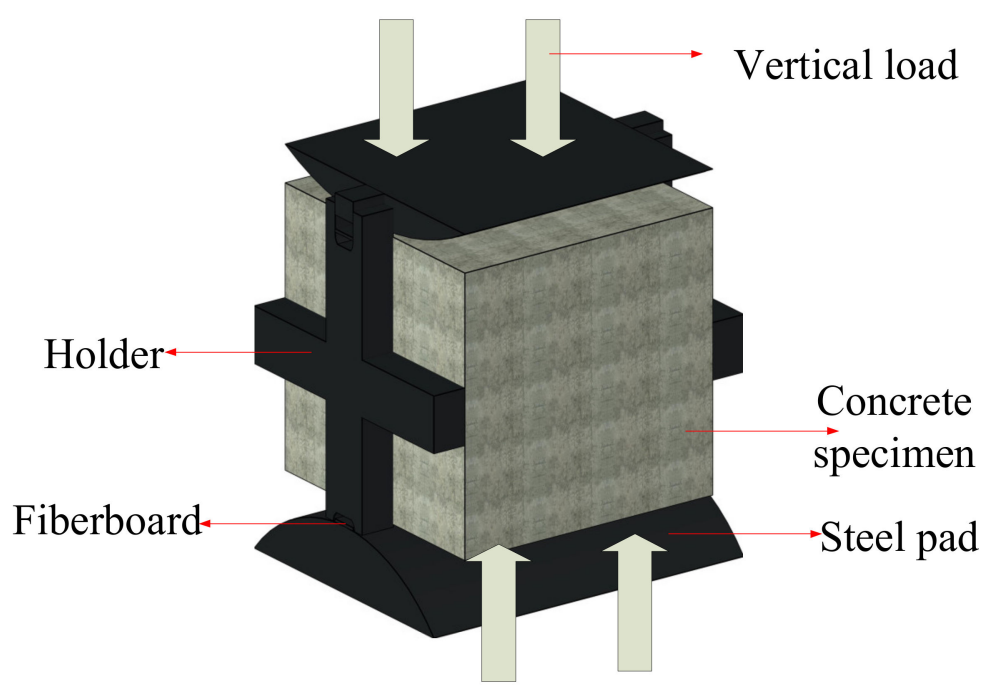

(a)

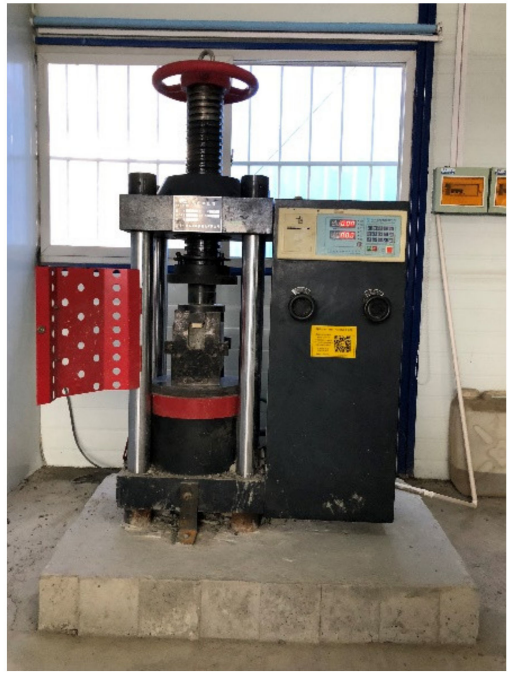

(b)

Figure 4. Setup for split tensile strength test: (a) Schematic diagram of test; (b) Photo of test.

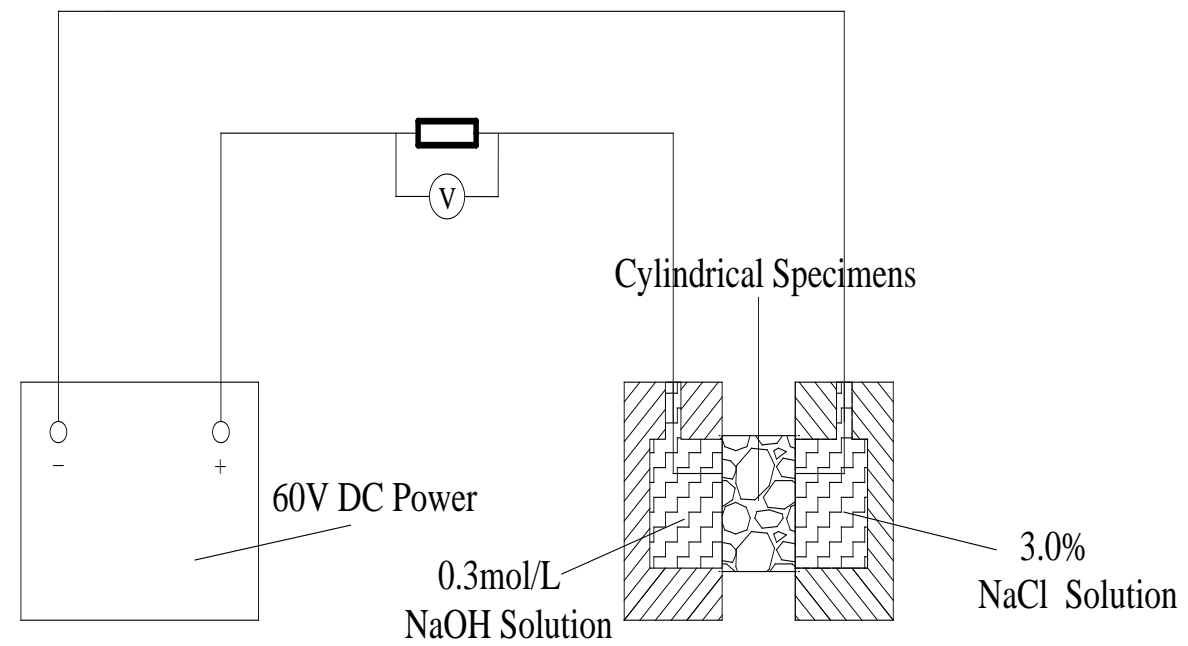

Figure 5. Setup for the chloride diffusion test.

Cylindrical specimens with a diameter of $100 \mathrm{~mm}$ and a height of $50 \mathrm{~mm}$ were used in the test. The solution was $0.3 \mathrm{~mol} / \mathrm{l} \mathrm{NaOH}$ and $3 \% \mathrm{NaCl}$. SX-DTL concrete chloride flux meter was used to record the electrification time and flux. The total electric flux of the concrete test block for $6 \mathrm{~h}$ was calculated according to Formula (2):

$$
Q=900 \times\left(I_{0}+2 I_{30}+2 I_{60}+\cdots+2 I_{t}+\cdots+2 I_{300}+2 I_{330}+I_{360}\right),
$$

where $Q$ is total flux through test block for $6 \mathrm{~h}(\mathrm{C}) ; I_{0}$ is initial flux (A), to $0.001 \mathrm{~A}$; $I_{t}$ is flux (A) at time $t$ (min), to $0.001 \mathrm{~A}$.

According to the Nernst-Plank equation, the relationship between chloride diffusion coefficient (CDC) and Q was established (Formula (3)):

$$
\mathrm{CDC}=2.57765+0.00492 \times \mathrm{Q} .
$$




\subsubsection{MIP Test}

The pore structure of concrete was analyzed by mercury intrusion porosimetry (MIP). When making the specimen, the concrete was knocked into several small test blocks with a length of about $2 \mathrm{~mm}$ to remove the coarse aggregate. The specimens were then soaked in anhydrous ethanol for $24 \mathrm{~h}$ to stop the hydration of cement and $\mathrm{MgO}$. Then, the specimens were placed in a vacuum drying oven at $50{ }^{\circ} \mathrm{C}$ for drying for $12 \mathrm{~h}$. Finally, the dried specimens were sealed in a plastic bag to prevent moisture from entering. During the test, the pore structure of two or three specimens was tested by MIP, and the effect of steel fibers and $\mathrm{MgO}$ on the pore structure was observed. By analyzing the experimental data of the pores, we could explain the variation law of tensile strength and compressive strength from the perspective of microstructure.

\subsubsection{SEM Test}

SEM test (JSM-65101A, Japan) was used to study the interface performance between steel fiber and substrate. All specimens used for SEM test were standardly cured for 28 days.

\section{Results}

\subsection{Failure Pattern of Concrete}

At the beginning of the split tensile test, the specimen was in the elastic stage, the surface was intact, and the deformation increased proportionally with the increase of load. With the continuous increase of the load, the vertical cracks appeared in the middle of the specimen, and then gradually extended to the bottom and the top, accompanied by the sound of splitting. At the end of test, the specimen was completely damaged. There were no obvious signs before the failure of RC and MC. After the cracks appeared on the surface, they extended rapidly and destroyed the concrete completely, showing obvious brittle failure. Finally, the specimen broke into two independent parts (Figure 6a,b). When the steel fiber was added into concrete, owing to the steel fiber limited the crack extension, the crack developed slowly before the destruction of SFRC, showing obvious ductility. Some fine cracks appeared around the long crack, and the specimen remained as a complete whole after the test, with only a small amount of block concrete falling from the surface (Figure 6c).

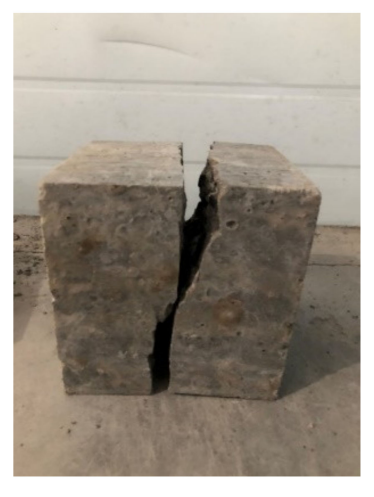

(a)

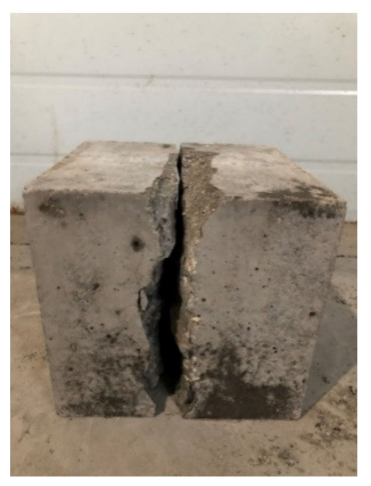

(b)

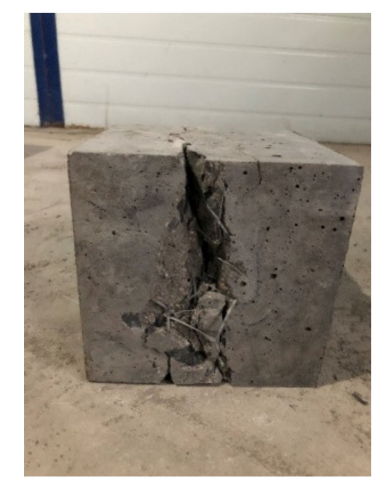

(c)

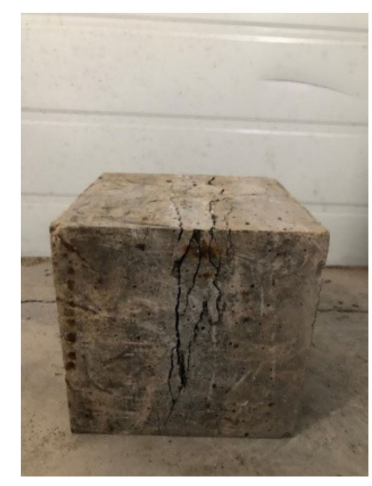

(d)

Figure 6. Failure pattern of concrete. (a) Reference concrete (RC); (b) $\mathrm{MgO}$ concrete (MC); (c) Steel fiber reinforced concrete (SFRC); (d) Steel fiber reinforced $\mathrm{MgO}$ concrete (SFRMC).

On the other hand, when the steel fiber and $\mathrm{MgO}$ were used simultaneously, the steel fiber restrained the expansion of $\mathrm{MgO}$ and generated self-stress, which improved the bite force between steel fiber and matrix, enhanced the strength of the interface between fiber and matrix, and significantly enhanced the crack resistance. Steel fiber made cracks became more evenly distributed. Instead of a single long and wide main crack in $\mathrm{RC}$, the crack developed into many parallel fine cracks in SFRMC. 
After the test, the SFRMC surface was smooth without concrete spalling, and the specimen split but did not separate (Figure 6d).

\subsection{Combined Action of Steel Fiber and MgO on Split Tensile Strength}

Figure 7 shows the split tensile strength of specimens with different mix proportions. Compared to $\mathrm{RC}, \mathrm{MgO}$ had a small impact on the strength of $\mathrm{MC}$ in the early stage, but it had a greater impact on the strength in the later stage. At 28 days, the tensile strength of MC was $4.4 \%$ higher than that of RC, and the improvement was mainly due to the hydration of $\mathrm{MgO}$. Compared to $\mathrm{RC}$, the tensile strength of SFRC had been significantly improved. The strength had increased by $29.7 \%$ at 28 days, which was the result of the steel fiber restrained crack extension.

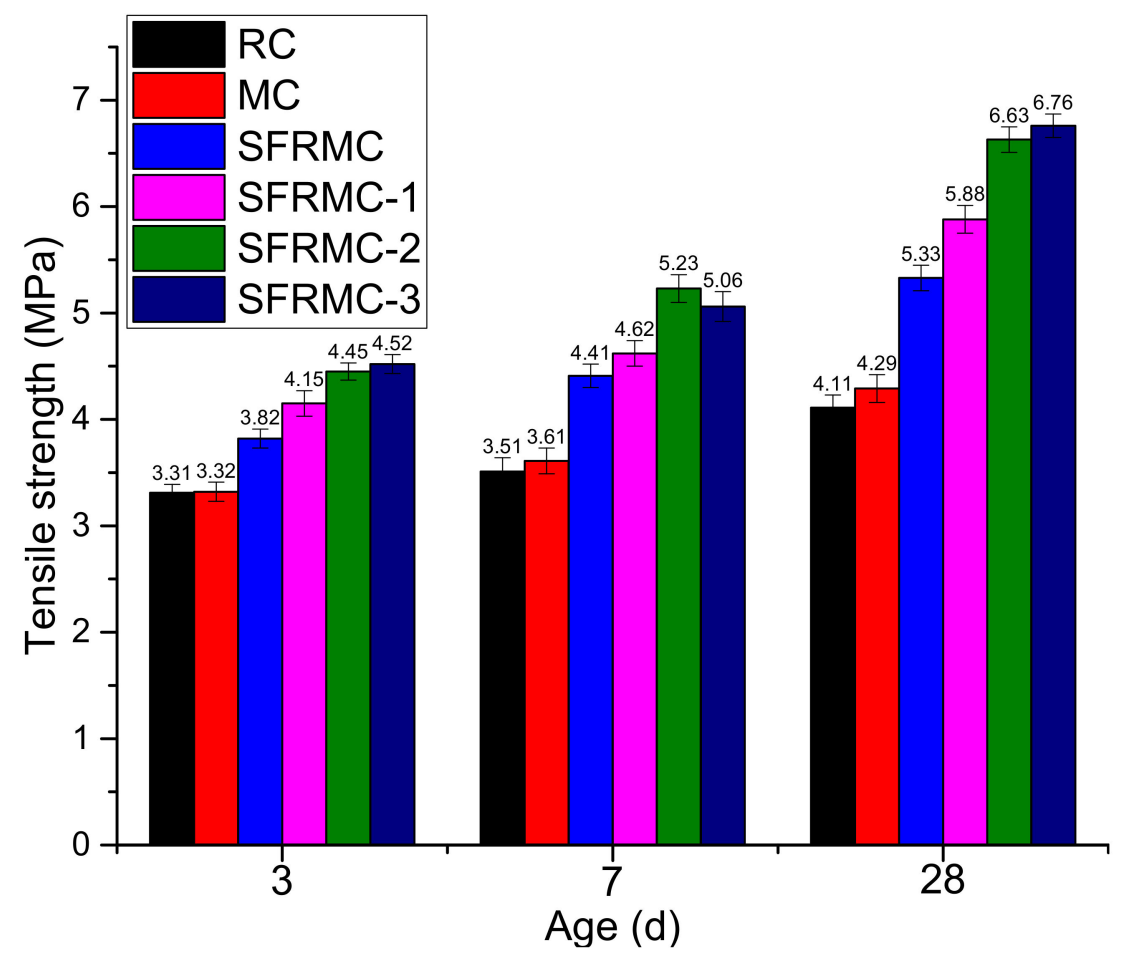

Figure 7. Split tensile strength of concrete.

On the other hand, when $\mathrm{MgO}$ and steel fiber were used at the same time, the tensile strength of SFRMC continued to increase. Compared to RC, the tensile strength of SFRMC-1, SFRMC-2, and SFRMC increased by $3.1 \%, 61.3 \%$, and $64.5 \%$, respectively. The tensile strength increased with the increase of steel fibers, and the growth rate was greater when the fiber was less than $1 \%$, and it would no longer increase significantly when it exceeded $1 \%$. Therefore, considering the cost of materials, we recommend using $8 \% \mathrm{MgO}$ and $1 \%$ steel fiber in constructions.

As we can see from the split tensile test, the concrete strength had been significantly improved under the combined action of steel fiber and $\mathrm{MgO}$. There are two main reasons for the increase. The first is that steel fiber limited the crack extension. When the cracks came out, the tensile stress was transferred from concrete to steel fiber, which restrained the further extension of cracks. The second reason is that the expansion of $\mathrm{MgO}$ was restrained by steel fiber, which resulted in self-stress. In the free state, the expansion energy produced by the hydration of $\mathrm{MgO}$ made the concrete expand outwards. However, under the constraint of steel fiber, the expansion energy was used to tension the fiber, resulting in self-stress. In this way, the tensile strength of concrete is obviously improved. 


\subsection{Combined Action of Steel Fiber and $\mathrm{MgO}$ on Chloride Diffusion Resistance}

Table 3 shows the chloride diffusion coefficients (CDC) of concrete at 3, 7, 28, 60, and 180 days. As can be seen from Figure 8, with the increase in curing time, CDC of concrete with different mixing ratios gradually decreased, and the descending rate in the early stage (0-28 days) was relatively larger, while the rate in the later stage gradually decreased. The results showed that early curing of concrete had a significant effect on CDC. As the curing age increased, the cementitious materials continued to hydrate, the densification of concrete became higher, and the pores in concrete were gradually reduced, which was beneficial to reduce CDC and improve the durability. No matter how we changed the amount of fiber and $\mathrm{MgO}$, the test results always obeyed this rule. Therefore, we suggest that in constructions, it is necessary to increase the time of early maintenance of concrete to improve the durability.

Table 3. Chloride diffusion coefficient of concrete specimens $\left(10^{-9} \mathrm{~cm}^{2} / \mathrm{s}\right)$.

\begin{tabular}{cccccc}
\hline \multirow{2}{*}{ Type } & \multicolumn{5}{c}{ Curing Age } \\
\cline { 2 - 6 } & $\mathbf{3 ~ d ~}$ & $\mathbf{7 ~ d}$ & $\mathbf{2 8 ~ d}$ & $\mathbf{6 0 ~ d}$ & $\mathbf{1 8 0 ~ d}$ \\
\hline Ref (RC) & 15.6 & 15.4 & 10.8 & 8.8 & 6.8 \\
8\%MgO (MC) & 15.4 & 15.2 & 10.7 & 8.4 & 6.7 \\
$0.5 \%$ Fiber (SFRC) & 14.9 & 14.5 & 9.8 & 8.0 & 6.2 \\
$8 \% \mathrm{MgO}+0.5 \%$ Fiber (SFRMC-1) & 14.8 & 14.0 & 8.6 & 7.7 & 5.1 \\
$8 \% \mathrm{MgO}+1 \%$ Fiber (SFRMC-2) & 13.7 & 11.2 & 6.4 & 6.2 & 4.8 \\
$8 \% \mathrm{MgO}+1.5 \%$ Fiber (SFRMC-3) & 11.1 & 10.3 & 7.2 & 6.2 & 4.9 \\
\hline
\end{tabular}

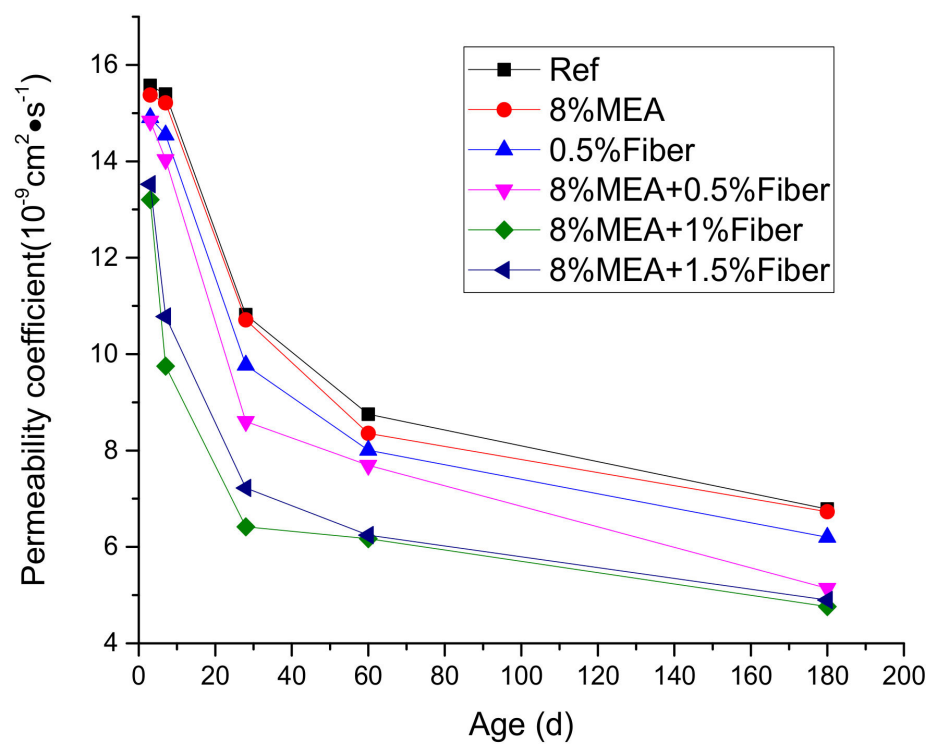

Figure 8. Changes of chloride diffusion coefficient.

Figure 8 shows that using $\mathrm{MgO}$ separately had little effect on CDC. At 180 days, CDC of MC was only $1.2 \%$ lower than that of RC. Different from $\mathrm{MgO}$, steel fiber had both positive and negative effects on the durability of concrete. The first was the positive effect. Steel fiber could effectively inhibit the generation of cracks and reduce CDC. The other was the negative effect. The addition of steel fiber increased the number of the interface between fiber and matrix and provided a channel for the transfer of chloride ions, which possibly improved CDC. It can be found from Table 3, when the steel fiber was less than $1 \%$, the positive factor played a major role. CDC decreased with the increase of steel fiber. Compared to RC, CDC of SFRC, SFRMC-1, SFRMC-2 decreased by $5.5 \%, 8.8 \%$, and $36.7 \%$, respectively at 7 days. However, when the steel fiber continued to increase, the negative effect gradually dominated, and CDC of SFRMC-3 was larger than that of SFRMC-2, which indicated that when steel fiber was too 
large, the negative effect caused by steel fiber was larger than the positive effect. Therefore, for SFRMC, the optimal content of steel fiber should not be more than $1 \%$. In the later stage of curing (180 days), owing to the combined action of MgO and steel fiber, CDC of SFRMC- 2 was $4.8 \times 10^{-9} \mathrm{~cm}^{2} / \mathrm{s}$, which was only $70.8 \%$ of RC, and the durability of concrete was obviously enhanced.

\subsection{Combined Action of Steel Fiber and $\mathrm{MgO}$ on Porosity of Concrete}

As an important part of concrete, the pore structure directly affected the mechanical properties and durability of concrete [24-26]. Therefore, the study on the effect of $\mathrm{MgO}$ and steel fiber on concrete is inseparable from the research on the pore structure. The pores can be classified into four categories: cementitious pores $(<10 \mathrm{~nm})$, transitional pores $(10-100 \mathrm{~nm})$, capillary pores $(100-1000 \mathrm{~nm})$, and macro pores $(>1000 \mathrm{~nm})$ [27]. Figure 9 shows the pore diameter distribution curve of concrete. Figure 10 shows the statistics of pore size.

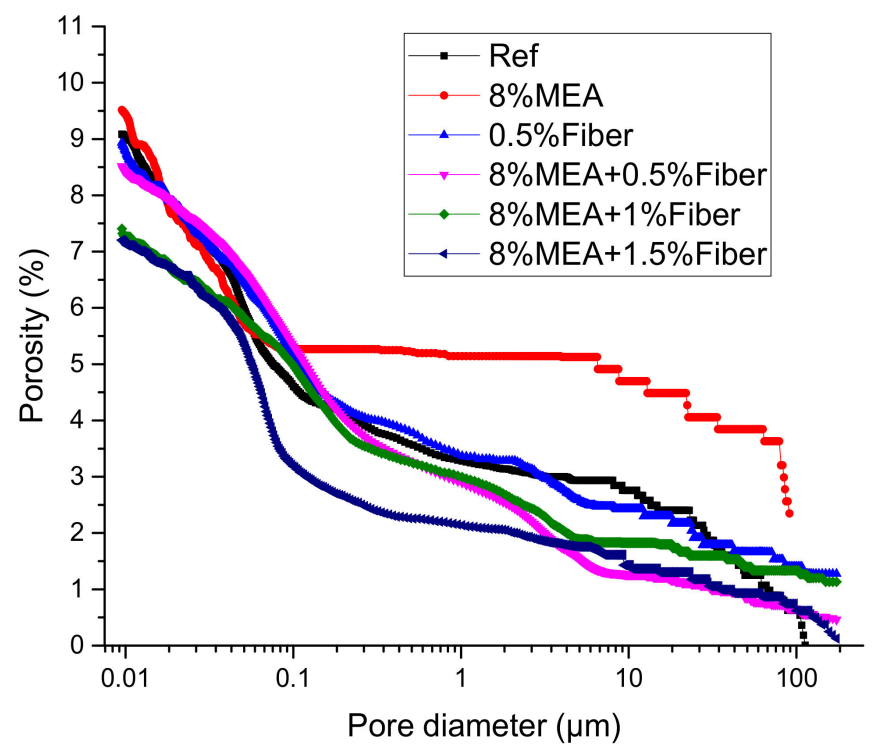

Figure 9. Porosity distribution curve of concrete.

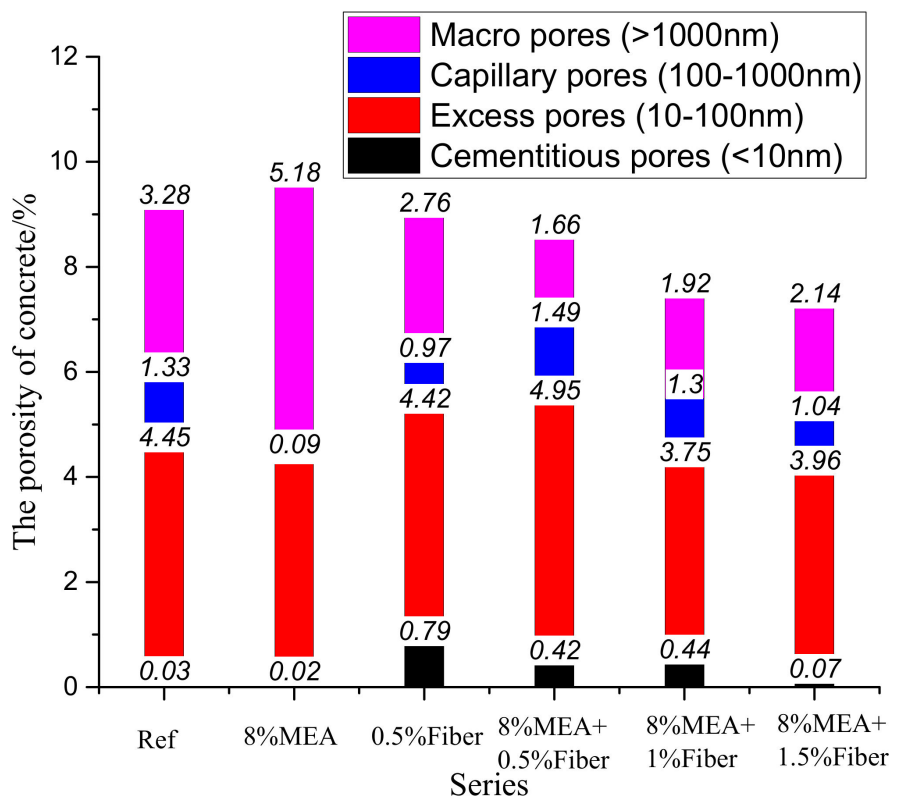

Figure 10. Statistics of concrete pore size. 
Figures 9 and 10 show that compared to RC, the porosity of MC increased by $5.7 \%$, indicating that the expansion of $\mathrm{MgO}$ is harmful to pore structure. The porosity of SFRC decreased by $1.5 \%$ compared to $\mathrm{RC}$, and the number of large pores decreased by $15.9 \%$, indicating that the steel fiber optimized the pore structure of concrete.

At the same time, when $\mathrm{MgO}$ and steel fiber were used together, the porosity continued to decrease. Compared to RC, the porosity of SFRMC-1, SFRMC-2, SFRMC-3 decreased by $6.2 \%, 18.4 \%$, and $20.6 \%$, respectively. In addition, the number of large pores was significantly reduced, cementitious and excessive pores were increased, and the connectivity of pores was reduced, which was also the main reason for the improvement of the chloride diffusion resistance of SFRMC.

\subsection{Combined Action of Steel Fiber and MgO on Interfacial Transition Zone}

To further analyze the principle of performance increase of SFRMC, the microstructure of concrete, especially the interfacial transition zone (ITZ) between fiber and matrix, was explored. The microstructure of ITZ with different mix ratios is shown in Figure 11. Figure 11 shows that in SFRC, there were obvious long and wide gaps in ITZ due to the shrinkage of matrix. Besides, tensile stress was produced because steel fiber restricted the shrinkage of matrix. In addition, when the tensile stress was larger than the tensile strength of concrete, the vertical crack was produced, leading to a reduction in durability.

Different from SFRC, when steel fiber and $\mathrm{MgO}$ were used at the same time, the wide gap at the interface disappeared. This change was mainly due to the extrusion and filling effect of $\mathrm{MgO}$. Owing to the expansion under the constraint of steel fiber, self-stress was generated in ITZ (Figure 12). The self-stress made the biting force and friction force greatly increased, made ITZ become dense, and the boundary become fuzzy.

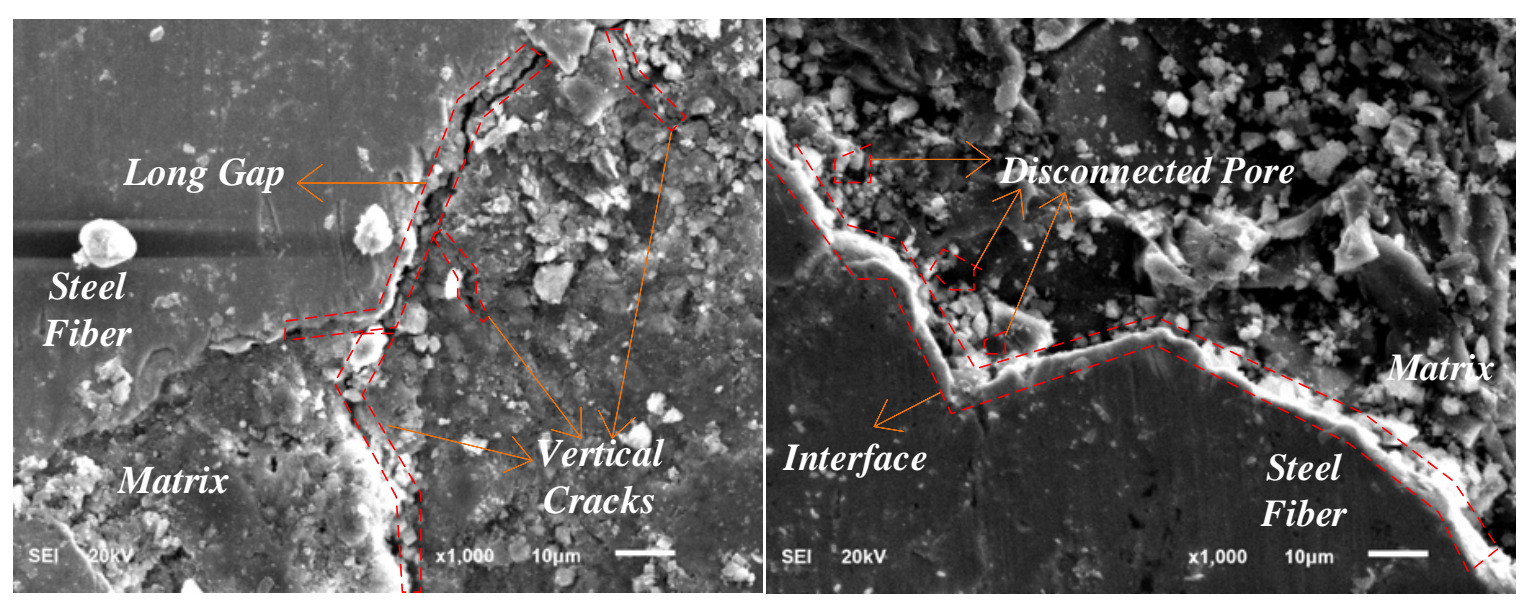

(a)

(b)

Figure 11. Interfacial transition zone (ITZ) between the steel fiber and matrix. (a) SFRC, (b) SFRMC-2. 


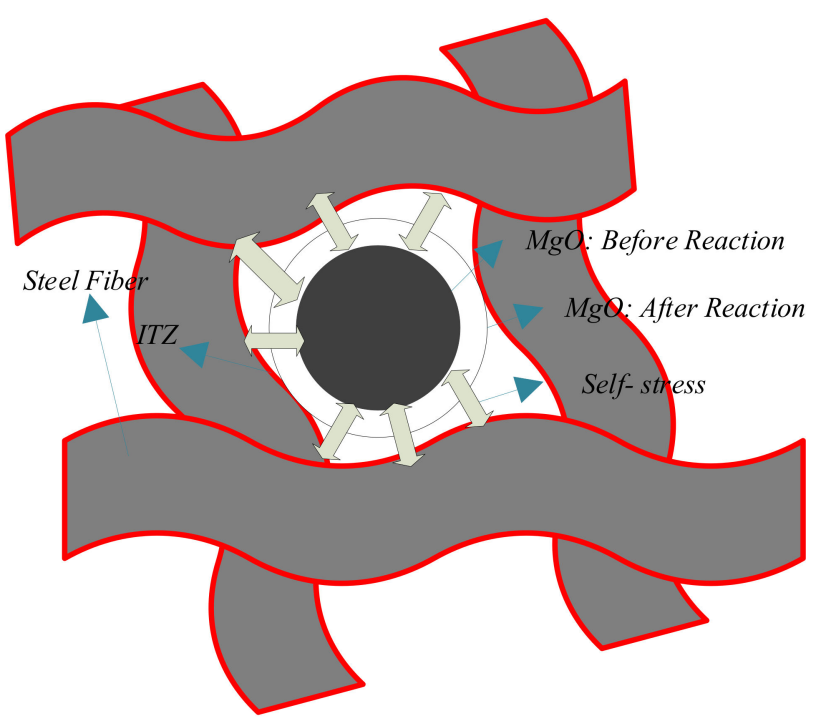

Figure 12. Self-stress caused by expansion extrusion at the interface.

\section{Conclusions}

Considering the defects of $\mathrm{MgO}$ and steel fiber when they were used separately, $\mathrm{MgO}$ and steel fiber were used at the same time in this paper. The influence of combined action on split tensile strength, chloride diffusion resistance, and pore structure of concrete was discussed in detail. Through detailed experimental research and theoretical analysis, the following conclusions could be drawn:

(1) For concrete, $\mathrm{MgO}$ and steel fiber could be used at the same time. In SFRMC, the steel fiber played the role of bearing and limiting expansion at the same time. The combination of $\mathrm{MgO}$ and steel fiber improved the split tensile strength and chloride diffusion resistance of concrete significantly. Compared to RC, the tensile strength of SFRMC-1, SFRMC-2, and SFRMC-3 increased by $3.1 \%, 61.3 \%$, and $64.5 \%$, and CDC decreased by $8.8 \%, 36.7 \%$, and $33.1 \%$, respectively.

(2) When steel fiber and $\mathrm{MgO}$ are used simultaneously, the two have a synergistic effect and the performance of the concrete is greatly improved. The combined action of steel fiber and $\mathrm{MgO}$ reduced the porosity of concrete, which could not be achieved by steel fiber and $\mathrm{MgO}$ separately. Compared to RC, the porosity of SFRMC-1, SFRMC-2, and SFRMC decreased by $6.2 \%, 18.4 \%$, and $20.6 \%$, respectively.

(3) Through the analysis of pore structure, the mechanism of performance enhancement of SFRMC was studied. Owing to the expansion of $\mathrm{MgO}$ was restrained by steel fiber, $\mathrm{MgO}$ changed from outward expansion to inward extrusion, resulting in filling and compaction effect. At the same time, self-stress was produced in ITZ, which improved the interfacial strength between steel fiber and matrix.

Author Contributions: Conceptualization, F.J. and M.D.; methodology, L.M.; software, F.J.; validation, F.J., M.D., L.M. and W.W.; formal analysis, M.D. and L.M.; investigation, F.J., M.D., L.M. and W.W.; resources, F.J. and M.D.; data curation, W.W.; writing-original draft preparation, F.J. and M.D.; writing—review and editing, F.J., M.D., L.M. and W.W.; visualization, F.J.; supervision, F.J., M.D., L.M. and W.W.; project administration, F.J.; funding acquisition, F.J. All authors have read and agreed to the published version of the manuscript.

Funding: This research was funded by Science and Technology Development Plan of Suzhou (SNG201904), National Key Research and Development Plan of China (2017YFB0309903-01) and Transportation Science and Technology Planning Project of Shandong Province (2018B37-02).

Acknowledgments: The authors would like to thank Zhongyang Mao from Nanjing Tech University for his precious contribution in the experiments.

Conflicts of Interest: The authors declare no conflict of interest. 


\section{References}

1. Feng, J.; Sun, W.; Zhai, H.; Wang, L.; Dong, H.; Wu, Q. Experimental Study on Hybrid Effect Evaluation of Fiber Reinforced Concrete Subjected to Drop Weight Impacts. Materials 2018, 11, 2563. [CrossRef]

2. Amini, F.; Barkhordari Bafghi M, A.; Safayenikoo, H.; Sarkardeh, H. Strength of Different Fiber Reinforced Concrete in Marine Environment. Mater. Sci. 2018, 24, 204-211. [CrossRef]

3. Ma, K.; Qi, T.; Liu, H.; Wang, H. Shear Behavior of Hybrid Fiber Reinforced Concrete Deep Beams. Materials (Basel, Switzerland) 2018, 11, 2023. [CrossRef]

4. Yang, G.; Wei, J.; Yu, Q.; Huang, H.; Li, F. Investigation of the Match Relation between Steel Fiber and High-Strength Concrete Matrix in Reactive Powder Concrete. Materials (Basel, Switzerland) 2019, $12,1751$. [CrossRef]

5. Alsaif, A.; Bernal, S.A.; Guadagnini, M.; Pilakoutas, K. Durability of Steel Fibre Reinforced Rubberised Concrete Exposed to Chlorides. Constr. Build. Mater. 2018, 188, 130-142. [CrossRef]

6. Gao, D.; Zhang, L.; Zhao, J.; You, P. Durability of Steel Fibre-Reinforced Recycled Coarse Aggregate Concrete. Constr. Build. Mater. 2020, 232, 117119. [CrossRef]

7. Afroughsabet, V.; Biolzi, L.; Monteiro, P.J.M. The Effect of Steel and Polypropylene Fibers On the Chloride Diffusivity and Drying Shrinkage of High-Strength Concrete. Composites Part B Engineering 2018, 139, 84-96. [CrossRef]

8. Guo, Y.; Hu, X.; Lv, J. Experimental Study on the Resistance of Basalt Fibre-Reinforced Concrete to Chloride Penetration. Constr. Build. Mater. 2019, 223, 142-155. [CrossRef]

9. Wang, Y.; Zhang, S.; Niu, D.; Su, L.; Luo, D. Strength and Chloride Ion Distribution Brought by Aggregate of Basalt Fiber Reinforced Coral Aggregate Concrete. Constr. Build. Mater. 2020, 234, 117390. [CrossRef]

10. Ramli, M.; Kwan, W.H.; Abas, N.F. Strength and Durability of Coconut-Fiber-Reinforced Concrete in Aggressive Environments. Constr. Build. Mater. 2013, 38, 554-566. [CrossRef]

11. Ding, Y.; Bai, Y. Fracture Properties and Softening Curves of Steel Fiber-Reinforced Slag-Based Geopolymer Mortar and Concrete. Materials (Basel, Switzerland) 2018, 11, 1445. [CrossRef]

12. Li, F.; Cao, C.; Cui, Y.; Wu, P. Experimental Study of the Basic Mechanical Properties of Directionally Distributed Steel Fibre-Reinforced Concrete. Adv. Mater. Sci. Eng. 2018, 1-11. [CrossRef]

13. Ige, O.; Barnett, S.; Chiverton, J.; Nassif, A.; Williams, J. Effects of Steel Fibre-Aggregate Interaction on Mechanical Behaviour of Steel Fibre Reinforced Concrete. Adv. Appl. Ceram. 2017, 116, 193-198. [CrossRef]

14. Xu, L.; Huang, C.; Liu, Y. Expansive Performance of Self-Stressing and Self-Compacting Concrete Confined with Steel Tube. J. Wuhan Univ. Technology-Mater. Sci. Ed. 2007, 22, 341-345. [CrossRef]

15. Hadi, M.N.S.; Al-Tikrite, A. Behaviour of Fibre-Reinforced RPC Columns Under Different Loading Conditions. Constr. Build. Mater. 2017, 156, 293-306. [CrossRef]

16. Choi, W.C.; Jung, K.Y.; Jang, S.J.; Yun, H.D. The Influence of Steel Fiber Tensile Strengths and Aspect Ratios on the Fracture Properties of High-Strength Concrete. Materials (Basel) 2019, 12, 2105. [CrossRef]

17. Mo, L.; Deng, M.; Tang, M.; Al-Tabbaa, A. MgO Expansive Cement and Concrete in China: Past, Present and Future. Cement Concrete Res. 2014, 57, 1-12. [CrossRef]

18. Polat, R.; Demirboğa, R.; Khushefati, W.H. Effects of Nano and Micro Size of CaO and MgO, Nano-Clay and Expanded Perlite Aggregate on the Autogenous Shrinkage of Mortar. Constr. Build. Mater. 2015, 81, $268-275$. [CrossRef]

19. Mo, L.; Deng, M.; Tang, M. Effects of calcination condition on expansion property of MgO-type expansive agent used in cement-based materials. Cem. Concr.Res. 2010, 40, 437-446. [CrossRef]

20. Dung, N.T.; Unluer, C. Improving the Performance of Reactive MgO Cement-Based Concrete Mixes. Constr. Build. Mater. 2016, 126, 747-758. [CrossRef]

21. Jiang, F.; Mao, Z.; Deng, M.; Li, D. Deformation and Compressive Strength of Steel Fiber Reinforced MgO Concrete. Materials 2019, 12, 3617. [CrossRef] [PubMed]

22. MOHURD. Standard for Test Method of Mechanical Properties of Ordinary Concrete, GB/T 50081-2016; China Standards Press: Beijing, China, 2016.

23. ASTM. Standard Test Method for Electrical Indication of Concrete's Ability to Resist Chloride Ion Penetration, C1202; ASTM International: West Conshohocken, PA, USA, 2012.

24. Zhang, M.; Li, H. Pore Structure and Chloride Permeability of Concrete Containing Nano-Particles for Pavement. Constr. Build. Mater. 2011, 25, 608-616. [CrossRef] 
25. Poon, C.S.; Kou, S.C.; Lam, L. Compressive Strength, Chloride Diffusivity and Pore Structure of High Performance Metakaolin and Silica Fume Concrete. Constr. Build. Mater. 2006, 20, 858-865. [CrossRef]

26. Güneyisi, E.; Gesoğlu, M.; Mermerdaş, K. Improving Strength, Drying Shrinkage, and Pore Structure of Concrete Using Metakaolin. Mater. Struct. 2008, 41, 937-949. [CrossRef]

27. Guo, J. The Theoretical Research of the Pore Structure and Strength of Concrete. Ph.D. Thesis, Zhejiang University, Hangzhou, China, 2004. 